7th International Symposium on Superalloy 718 and Derivatives Edited by: E.A. Ott, J.R. Groh, A. Banik, I. Dempster, T.P. Gabb, R. Helmink, X. Liu, A. Mitchell, G.P. Sjöberg, and A. Wusatowska-Sarnek TMS (The Minerals, Metals \& Materials Society), 2010

\title{
Modeling and Simulation of Alloy 718 Microstructure and Mechanical Properties
}

\author{
David Furrer, Robert Goetz, and Gangshu Shen
}

Rolls-Royce; P.O. Box 420, Speed Code S-48, 2001 South Tibbs Avenue; Indianapolis, Indiana, 46206-0420, USA

Keywords: Modeling, Simulation, Microstructure, Mechanical Properties, Prediction, Alloy 718

\begin{abstract}
Alloy 718 is a unique superalloy that has been in use for a number of years. It also has the distinction to be utilized throughout the aerospace and general industrial communities. The applications for this material are often very unique and require tailoring of the microstructure and subsequently the mechanical properties to meet these specific needs. To support optimization of Alloy 718 mechanical properties and performance, considerable work has been conducted by the materials community to develop materials and manufacturing process models to aid in the simulation and prediction of the microstructure and mechanical properties of components produced from this alloy. This paper will review various modeling and simulation tools and applications to Alloy 718. This complex alloy is continuing to see optimization efforts through the use of modeling and simulation to support new and enhanced application requirements.
\end{abstract}

\section{Introduction}

Modeling and simulation tools and computational methods are being developed and used for a wide range of applications. Models that describe the behavior of microstructure evolution are being linked to manufacturing process simulations to enable predictive assessment and analysis for specific component applications. The models that are being created are of various types, including physics-based mechanistic models, experiment-based phenomenological models or input-output data-based statistical models.

These computational tools are being applied to nearly every material for the purpose of enhancing material and component capability, and reducing material, process or component development time and/or cost. Materials are currently being designed and optimized through the use of computational tools. [1,2,3] Use of computational tools has provided the ability to seek both cost and performance enhancements of new alloys for the broad range of nickel-base superalloy classes for turbine engine disk applications. The application of computational methods can enable the assessment of alloy inherent, manufacturing process and application lifecycle costs, which can open up the ability to holistically design new components for optimum performance and total life-cycle costs.

Recent work has shown significant reduction in new alloy development time through the application of computational methods. Similarly, manufacturing processes are being simulated along with material response to enable process optimization and control schemes to produce unique, location-specific designed components, such as hybrid-microstructure (dualmicrostructure) disks for turbine engine applications [4]. 
Alloy 718 is a very common nickel-base superalloy, and had provided the basis for a number of modeling and simulation efforts. The application of this alloy and its derivatives to materials and process modeling development has been in part due to the availability of this material and the many potential uses of modeling and simulation tools aimed at enhancing the numerous components produced from this material. This alloy and its derivatives, however, actually represent a significant challenge to the modeling and simulation community. The alloy has a rather complex phase make-up, with equilibrium and non-equilibrium phase generation and manipulation during processing. This results in complex thermodynamic and kinetic understanding and description.

A review of the various metallurgical and manufacturing related processes has been conducted in light of modeling and simulation. An assessment of the activities and associated capability to predict the microstructural evolution and accompanied mechanical property development within Alloy 718 material has been conducted. There has been significant effort to model and simulate the evolution of structures and properties in this alloy, but further work remains to develop industry-wide standards for these engineering methods and to establish standard validation techniques to ensure accurate and reliable predictions, including variants of Alloy 718 and new and novel processing methods.

\section{Modeling and Simulation Methods}

Models and modeling techniques for materials and manufacturing processes are continuing to evolve. Pragmatic relationships that describe the observed interaction and dependency of specific parameters on resultant observations have been developed and utilized for many years, such as the Hall-Petch relationship for strength as related to alloy grain size. But as further mechanisms are defined that control specific observations and as engineering requirements increase for further prediction accuracy, increasingly complex, physics-based models are emerging, such as crystal-plasticity and dislocation dynamics modeling to predict the deformation, strain localization, and microscopic and macroscopic properties of materials.

There are a wide range of models that describe specific metallurgical phenomenon. [5] These models often times, especially when the model is complicated and incorporates numerous mechanisms, require the development of material-specific parameters, such as grain boundary energies, anti-phase boundary energies, multi-component mobilities etc., which are difficult to measure and establish. This results in mechanistic models that require fitting, or inverse calculation of specific parameters to establish "calibrated" models for specific alloys and materials systems.

Models for thermodynamic prediction of phase equilibria have been established and are used in conjunction with other mechanistic models to predict phase and microstructure evolution. Diffusion-based mobility models have been developed and deployed for numerous hightemperature simulation applications. Both the thermodynamic and kinetic models require databases to enable calculation of free energies and mobility information. While these models are physics-based, experimental data and database generation is required for actual application to industrial materials and processes.

Microstructure evolution models are also evolving from phenomenological approaches, though extremely pragmatic and accurate, to more complex physics-based methods that provide greater 
insight into the specific mechanisms that are controlling the evolution of the microstructure and its morphology. Johnson, Mehl, Avrami and Kolomogorov-type (JMAK) models have been used for many years to predict the recrystallization of metallic materials. [6,7,8] The prediction of rate of recrystallization and recrystallized grain size are a function of the starting grain size, temperature, strain rate (or derived parameters, such as the Zener-Holloman parameter, which is the temperature compensated strain rate), strain as well as the post deformation hold time. These types of models have been linked with finite element method codes to enable simulation of grain structure evolution as a function of deformation process employed. More recent work to predict microstructure evolution has been in the form of phase-field modeling [9] and cellular automata [10], or cellular automata linked to finite element methods (CAFE methods) [11]. These more physics-based grain structure evolution models require further understanding of the mechanisms and often rely on other models to provide input data for prediction, which include thermodynamic and mobility predictions as a minimum.

Precipitation models also range from phenomenological to mechanistic. Recent work has shown that mechanistic models that utilize the mean-field approximation do provide useful prediction of precipitate formation. [12] Further enhancements for these tools have lead to modifications of the description of precipitation and subsequent growth of particles on grain boundaries preferentially to intra-granular precipitates. And as with grain structure evolution, other mechanistic modeling approaches have been evolving to enable accurate prediction of precipitate formation and growth along with detailed description of morphology via phase-field type methods. [13].

Mechanical property prediction is of great interest to component designers. Designers often do not care about the prediction of microstructure, but mechanistic or microstructure-based prediction of mechanical properties require these types of models to be developed and validated as the initial step. Tensile and creep models based on microstructure have been developed and deployed for many alloy systems. [14, 15, 16,17] These models can be derived and applied to alloys with average microstructural properties. The issue of microstructure description is significant. Average microstructure properties can not be readily applied to other properties, where variation in the distribution of the individual grain size and crystal orientation relative to the applied stress direction and nearest neighbors primarily control the distribution of properties and of great importance to designers, the minimum properties. The mechanical properties that require this type of microstructural understanding (absolutely or statistically) are low-cycle fatigue, high-cycle fatigue and dwell-fatigue, with the latter also requiring understanding of environmental affects and interactions. There is considerable work on-going to develop mechanistic fatigue models based on crystal-plasticity methods. [18, 19] These methods are being deployed to production use for a range of application and microstructure control and other component lifing applications [20].

The linking of these models to industrial applications requires the use of computational codes that link manufacturing process simulation with these materials models to enable practical simulation of evolving microstructure and mechanical properties. A range of commercial off the shelf (COTS) software is now available to conduct materials and process simulations based on the various models that describe the metallurgical phenomena. The fundamental models can be utilized for a wide range of applications. [21] Other significant component properties, which are material, component geometry and manufacturing path dependent, such as bulk residual stress, are now being simulated and predicted to enable use throughout industry for process and component design optimization. 


\section{Review of Modeling and Simulation Applications to Alloy 718 and Derivatives}

Alloy 718 and its derivatives have been utilized for a number of model development and simulation tool demonstration efforts. These efforts have been conducted either for specific model development and demonstration, or for necessitate specific Alloy 718 or derivative material and component to be manufactured in an optimum manner. An assessment of the modeling and simulation efforts applied specifically to Alloy 718 and its derivatives has been conducted relative to specific metallurgical phenomena and processing methods.

Casting Simulation:

Models to predict the solidification of large industrial ingots have been developed by several groups. An effort has been previously conducted to predict the eletroslag remelting and solidification of large ingots of Alloy 718. [22] Within this modeling effort, process boundary conditions were carefully characterized along with the thermo-physical properties of molten Alloy 718. This model includes expressions for temperature and fluid flow, magnetic flux and magnetic stirring effects and solidification. The developed model can support prediction of defect formation including shrinkage porosity and chemical segregation. Models of this type are being utilized to develop and control robust melting parameters for production ingots of Alloy 718 and other materials.

Solidification of alloys is often accompanied by microsegregation and interdendritic porosity. A study of dendritic solidification of Alloy 718 has been performed in which mass transport of hydrogen and nitrogen have been linked to the formation of local porosity. [23] This model can be utilized to predict and subsequently control the formation of microporosity in this alloy.

Another effort focused on the prediction of porosity in cast equiaxed Alloy 718. [24] Commercial codes were applied to casting development efforts. Difficulties in developing accurate thermal models and appropriate validation efforts were reviewed.

Novel casting methods have been developed for the manufacture of superalloy materials including Alloy 718. Spray forming has been studied by researchers with specific aim to predict the resultant grain size from this process. [25] The coarsening of the gamma grains was found to follow an Oswald ripening type expression as the material is built-up with droplets and layers of semi-molten material.

$$
\mathrm{d}^{\mathrm{n}}-\mathrm{d}_{0}^{\mathrm{n}}=\mathrm{Kt}
$$

Where $\mathrm{d}$ is the average grain size after heat treatment time $\mathrm{t}, \mathrm{d}_{0}$ is the initial grain size, $\mathrm{K}$ is the temperature dependent coarsening rate constant, and $\mathrm{n}$ is the coarsening exponent.

An integrated model consisted of four sub-models: (1) an atomization model; (2) a droplet spray model; (3) a droplet deposition model; and (4) a porosity model has been developed and validated against experiments of the spray formed Alloy 718. [26] This complex model incorporates the physics of several phenomena into a predictive tool that provides greater understanding of spray forming processes.

Additive manufacturing processes are becoming critical for original manufacturing processes and for repair efforts. An effort to model and simulate the Laser Direct Deposition process has been 
conducted. [27] Powder and heat flow models were developed and coupled to enable for accurate prediction of melt pool size.

Forging Simulation:

For the simulation of forging processes, material and process boundary conditions are required. Constitutive models for the flow behavior of Alloy 718 and its derivatives have been developed and published by a number of researchers. Early investigations resulted in development and application of empirical equations to describe the flow stress of Alloy 718. [28] The empirical relationships based on isothermal upset testing was shown to successfully predict the load-time histories during large-scale non-isothermal forging processes.

During the investigation of rotary forging of Alloy 718 disk components, a model for the flow stress of Alloy 718 has been developed. [29] The flow properties were determined to follow the form:

$$
\begin{aligned}
& \sigma=\sigma_{\mathrm{P}}\left[1-\exp \left(-\mathrm{C}_{\varepsilon}\right)\right]^{1 / 2}-\left(\sigma_{\mathrm{P}}-\sigma_{\mathrm{S}}\right) \\
& \cdot 1-\exp \left[-\ln 2\left[\frac{\varepsilon-\beta_{\varepsilon P}}{\varepsilon_{\mathrm{P}}}\right] \mathrm{m}\right], \\
& \sigma_{\mathrm{P}}=\mathrm{a}_{1} \dot{\varepsilon}^{\mathrm{b} 1} \exp \left[\frac{\mathrm{c}_{1} \mathrm{Q}}{\mathrm{RT}}\right], \\
& \sigma_{\mathrm{S}}=\mathrm{a}_{2} \dot{\varepsilon}^{\mathrm{b} 2} \exp \left[\frac{\mathrm{c}_{2} \mathrm{Q}}{\mathrm{RT}}\right], \\
& \mathrm{C}=\mathrm{a}_{3} \dot{\varepsilon}^{\mathrm{b} 3} \exp \left[\frac{\mathrm{c}_{3} \mathrm{Q}}{\mathrm{RT}}\right], \\
& \varepsilon_{\mathrm{P}}=\mathrm{a}_{4} \varepsilon^{\varepsilon^{64}} \exp \left[\frac{\mathrm{c}_{4} \mathrm{Q}}{\mathrm{RT}}\right]
\end{aligned}
$$

where $\sigma$ is the flow stress, $\sigma_{\mathrm{P}}$ is the peak flow stress, $\sigma_{\mathrm{S}}$ is the steady state flow stress, $\mathrm{C}$ is the amount of dynamic recovery, $\varepsilon_{\mathrm{P}}$ is the peak strain, $\varepsilon$ is the strain, $\varepsilon$ is the strain rate, and $\mathrm{T}$ is the temperature.

The material constants are determined to fit the data of reference 46 which are shown in Table 1. The activation energy $\mathrm{Q}=400 \mathrm{~kJ} / \mathrm{mol}, \mathrm{R}$ is the gas constant, and coefficients $\mathrm{m}$ and $\beta$ are 1.68 and 0.83 respectively.

Table 1. Material constants associated with equations 1-5. [29]

\begin{tabular}{ccccc}
\hline $\mathrm{i}$ & 1 & 2 & 3 & 4 \\
\hline $\mathrm{a}_{\mathrm{i}}$ & 0.928 & 2.03 & 19.2 & 0.0046 \\
$\mathrm{~b}_{\mathrm{i}}$ & 0.17 & 0.165 & 0.045 & 0.1238 \\
$\mathrm{c}_{\mathrm{i}}$ & 0.125 & 0.106 & 0.0163 & 0.124 \\
\hline
\end{tabular}


A similar constitutive model for the flow behavior of Alloy 718 has been presented by other researchers. [30] The materials constants for equations 2-6 have been reported to be the same, and are listed in Table 2 along with constants utilized for expressions to predict strain to 50\% recrystallization, recrysallized grain size and grain size during grain growth.

Table 2. Material constants associated with equations 2-6. [30]

\begin{tabular}{ccccccc}
\hline $\mathrm{i}$ & 1 & 2 & 3 & 4 & 5 & 6 \\
\hline $\mathrm{a}_{\mathrm{i}}$ & 0.928 & 2.03 & 19.2 & 0.029 & 1,300 & $1.58 \times 10^{16}$ \\
$\mathrm{~b}_{\mathrm{i}}$ & 0.17 & 0.165 & 0.045 & 0.2 & 0.124 & \\
$\mathrm{c}_{\mathrm{i}}$ & 0.125 & 0.106 & 0.0163 & 0.058 & & \\
\hline
\end{tabular}

The linking of location-specific microstructure effects and associated location-specific flow stress behavior to macroscopic observed flow stress has been developed for Alloy 718.[31] In this approach, the apparent flow stress is the weighted sum of the local stress stresses based on volumetric contribution of the different local microstructures as follows;

$$
\bar{\sigma}=\mathrm{x}_{0} \sigma_{0}+\mathrm{x}_{1} \sigma_{1}+\cdots+\mathrm{x}_{\mathrm{n}} \sigma_{\mathrm{n}} \sum_{\mathrm{i}=0}^{\mathrm{n}} \mathrm{x}_{\mathrm{i}} \sigma_{\mathrm{i}}
$$

where $\bar{\sigma}$ is the apparent flow stress; $x_{i}$ and $\sigma_{i}$ are the volume contributions and local flow stresses of different microstructures, respectively.

As similar approach to the prediction of the flow stress during forging of Alloy 718 has been presented by Zhang et.al. [32] Quantitative measurement of grain sizes, including sizes and volume fractions of IN718 material were obtained on rapidly quenched samples. The contribution to the flow stress of each population of grain size was used to predict the effective material flow stress.

Efforts to link JMAK-type grain size models and FEM deformation models have been conducted with an aim to establish control methods for optimum forging processes. [33] Within this effort, control of processing parameters was established through linking the dynamic materials models with an artificial neural-network (ANN). This approach was developed for Alloy 718 and provides a potential means of establishing open-loop control methods aimed at stable flow and optimum microstructure evolution.

In addition to fully understanding the behavior of the forging workpiece material, understanding of the forging process and tooling is also critical. Efforts to establish accurate thermal models for forging processes were conducted with controlled experiments. [34] This effort resulted in establishing interface heat transfer coefficients between Alloy 718 and forging tooling. This information is critical for other efforts aimed at accurate prediction of thermal history during forging.

Material models have been linked with FEM models to simulate bulk deformation and microstructure evolution in high strain-rate hammer forging of turbine engine disks. [35] These efforts were extremely successful in predicting the evolution of microstructure basis dynamic and meta-dynamic recrystallization, as well as grain growth resulting from adiabatic heating during the high strain-rate manufacturing process. 
Welding and Joining Simulation:

Joining of Alloy 718 and its derivatives is very important for many applications. An energybased inertia welding model has been developed that has been shown to provide reasonable temperature prediction capabilities. [36] Angular velocity was the parameter that was shown to have the most influence on interface heat generation and could be used to optimize inertia weld properties.

Grain Structure Evolution Modeling:

The grain structure of Alloy 718 and its derivatives has been modeled by a number of researchers. Models to predict the evolution of the grain structure have been developed and deployed primarily for deformation processes. Detailed studies on the evolution of microstructure have been conducted using very controlled experimental techniques and characterization methods. [37, 38]

Johnson, Mehl, Avrami and Kolomogorov-type (JMAK) models have been developed for both Alloy 718 and Alloy 718Plus. There have been several groups that have develop JMAK-type models for Alloy 718. An effort linked to the turbine engine blade forging microstructure prediction and optimization effort has developed a series of models that were linked to process simulation efforts.[39] The JMAK-type models have a general form as follows [39]:

Critical strain

$$
\begin{aligned}
& \varepsilon_{\mathrm{C}}=8.87 \times 10^{-4} \mathrm{~d}_{0}{ }^{0.2} \mathrm{Z}^{0.099} \text { when } \varepsilon \geq 0.01 \mathrm{~s}^{-1} \\
& \varepsilon_{\mathrm{C}}=9.57 \times 10^{-6} \mathrm{~d}_{0}{ }^{0.196} \mathrm{Z}^{0.167} \text { when } \varepsilon<0.01 \mathrm{~s}^{-1}
\end{aligned}
$$

Meta-dynamic recrystallization

$$
\begin{aligned}
& \mathrm{X}_{\mathrm{mdyn}}=1-\exp \left[-\ln 2\left[\frac{\mathrm{t}}{\mathrm{t}_{0.5}}\right]^{1},\right. \\
& \mathrm{t}_{0.5}=1.7 \times 10^{-5} \mathrm{~d}_{\mathrm{o}}^{0.5} \varepsilon^{-2.0} \varepsilon^{-0.08} \times \exp (12000 / \mathrm{T}) \\
& \mathrm{d}_{\mathrm{mdyn}}=8.28 \mathrm{~d}_{\mathrm{o}}^{0.29} \varepsilon^{-0.14} \mathrm{Z}^{-0.03}
\end{aligned}
$$

Dynamic recrystallization

$$
\begin{aligned}
& \mathrm{X}_{\text {dyn }}=1-\exp \left[-\ln 2\left[\frac{\varepsilon}{\varepsilon_{0.5}}\right]^{1.68}\right], \text { where } \mathrm{T} \leq 1038 \mathrm{C}, \varepsilon_{0.5}=0.037 \mathrm{~d}_{0}^{0.2} \mathrm{Z}^{0.058} \\
& \mathrm{X}_{\text {dyn }}=1-\exp \left[-\ln 2\left[\frac{\varepsilon}{\varepsilon_{0.5}}\right]^{1.90}\right], \text { where } \mathrm{T} \geq 1038 \mathrm{C}, \varepsilon_{0.5}=0.029 \mathrm{~d}_{0}{ }^{0.2} \mathrm{Z}^{0.058}
\end{aligned}
$$




$$
\mathrm{d}_{\mathrm{dyn}}=1.301 \times 10^{3} \mathrm{Z}^{-0.124}
$$

Grain growth

$$
d^{3}-d_{o}{ }^{3}=9.8 \times 10^{19} t \exp (-437000 / R T)
$$

Another version of the Avrami-type models was developed for Alloy 718. [31] The recrystallized grain size in this study was predicted to have a strong linkage to strain rate and temperature.

Studies of metadynamic recrystallization of Alloy 718 indicate that metadynamic recrystallization can be predicted to result when the dislocation density after deformation is above a critical value. [40]

The grain size model for Alloy 718 as determined by $\mathrm{Yu}$ and co-workers [29] is given by the same expressions as listed in equations 7-15.

JMAK-type equations for Alloy 718 were also reported by Ma et. al. [30] These equations were linked with DEFORM and utilized to predict the resultant microstructure in forged pressure vessel domes.

Similar to Alloy 718, researchers have developed static and dynamic recrystallization models for Alloy 718Plus using JMAK-type expressions. [41] Different equations for this alloy were reported depending on whether delta-phase was present. Additionally, grain growth for Alloy 718Plus has been shown to be limited below 975C.

An approach to track the dislocation density as a function of strain has been proposed and utilized to predict the microstructure evolution in Alloy 718. [42] The relationship between the increase in deformation strain $\mathrm{d} \varepsilon$ and the increase in dislocation density $\mathrm{dn}$ in this work is given by:

$$
\mathrm{dn}=\left(6.6 \times 10^{14}\right) \mathrm{d} \varepsilon
$$

Additional efforts have been conducted to model the deformation of Alloy 718 with dislocation density-based constitutive equations. [43] Avrami-type microstructure evolution models have been developed and were shown to be successful in predicting resultant forged microstructures.

Work has been conducted to develop a model for the recrystallization of Alloy 718 while taking precipitation of delta into account. [38, 44] This modeling approach is based on a number of factors including delta phase fraction and particle size, meso-scale microstructural units (MSU), grain density in the volume, grain diameter in the volume, free dislocation density, grain volume, MSU volume, grain surface, grain boundary surface density, sub-boundary surface density, twin boundary surface density, and density of dislocations stored in sub-boundaries. This model has been used successfully to predict fraction recrystallized and recrystallized grain size. The models incorporate a Zener pinning coefficient that is also dynamic with continued straining.

Other methods to predict the grain structure evolution in forged Alloy 718 have been developed. An approach has been reported based on fuzzy mathematical methods linked to finite element 
methods for prediction of forging grain sizes. [45] This approach enable the coupled linkage of deformation process and microstructural evolution which are inter-dependant.

An approach to develop deformation parameters which result in stable flow through efficiency in power dissipation has been developed for Alloy 718 along with models for flow stress and microstructure evolution. [46] The expression for grain size evolution in the meta-dynamic recrystallization range was reported to be:

$$
\begin{aligned}
& \mathrm{d}=\mathrm{c}^{-\mathrm{p}} \exp (-\mathrm{Q} / \mathrm{RT}) \\
& \quad\left(\text { where } \mathrm{c}=5.98 \times 10^{10}, \mathrm{p}=0.028 \text { and } \mathrm{Q}=240 \mathrm{~kJ} / \mathrm{mole}\right)
\end{aligned}
$$

\section{Precipitation Modeling:}

Precipitation heat treatment and control of precipitate phase type, quantity, location and morphology are all critical to controlling final mechanical properties in Alloy 718 . Thermodynamic and kinetic models have been linked to enable prediction of the TTT diagram for Alloy 718. [47] This model and computer-based simulation tool has been shown to be able to predict the precipitation of gamma-prime, gamma-double prime and delta. The developed model has the ability to take into account variations in heat-heat chemistry and local chemistry variations.

\section{Bulk Residual Stress Modeling:}

Residual stresses that result from heat treatment quenching processes can be of significant issue relative to subsequent machining operations and resultant distortions, and relative to component life assessment. Internal residual stresses result from localized yielding during the quenching process due to thermal stresses from non-uniform cooling. A number of programs have been aimed at development of residual stress models for Alloy 718. One effort demonstrated the capability of accurately predicting bulk residual stresses and validating through neutron diffraction measurement techniques. [48] Residual stresses in the range of the yield strength were developed in the demonstrated component.

In a similar effort, a full-scale Alloy 718 disk component was solution heat treated and quenched, and assessed by through thickness neutron diffraction measurement to compare to model predictions. [49] A fully coupled thermo-mechanical finite element model was successful in predicting the bulk residual stresses in the full-scale disk component. Complexities in disk geometry introduced complexities within the internal stress state making measurement difficult, but readily possible if all stress types and orientation were taken into account. Residual stresses in excess of the yield stress were present in the disk due to the presence of hydrostatic stresses.

\section{Mechanical Property Modeling:}

Fatigue models of various forms have been developed for Alloy 718. An effort to develop a model for Alloy 718 to support simulation of fatigue behavior has been conducted. [50] Both kinematic hardening and Bodner-Partom models were used to predict the cyclic behavior of test specimens. Bodner-Partom type model was successful in describing the form and magnitude of the fatigue hysteresis loops. Linkages of these materials models to finite element models enabled the prediction of crack opening stresses and crack growth rates. 
Similar efforts to predict the fatigue properties for an Alloy 718 disks showed that finite element modeling is very useful in assessing location-specific (notch region, etc.) stresses and material behavior.[51, 52] Like the prior examples of fatigue modeling, a empirical description of the mechanical properties of Alloy 718 was used and was not microstructure sensitive.

Microstructure based fatigue models have been developed for Alloy 718. [53, 54] These efforts indicate that fatigue crack nucleation is strongly related to slip length, grain orientation and inclusion content. The formation of fatigue cracks are strongly associated with persistent slip bands and the amount of cumulative local plastic strain.

Holistic Design Simulation:

The integration of a series of models to predict the evolution of microstructure and subsequently mechanical properties is of great interest and importance for industrial applications. Specific models for the evolution of microstructure and mechanical properties have been developed and deployed for specific sectors of the overall manufacturing supply-chain. For designers to readily utilize materials and process modeling predictive capabilities to assess and optimize component designs, the entire manufacturing route that influences the final component location-specific microstructure and mechanical properties must be simulated in an integrated manner.

A focused effort to link models for the manufacture of critical rotating structural components has been previously conducted and reported on, which included linking of models for vacuuminduction melting (VIM), vacuum-arc remelting (VAR), homogenization heat treatment, cogging, forging, final heat treatment, and machining of Alloy 718. [55] Cellular automata grain size models and models similar to the previously noted methods were applied. The effort was successful in demonstrating the linkage of a series of models and carrying the microstructure evolution through the major manufacturing processes that affect the final component properties and capabilities. This is an example of how future integrated computational materials engineering (ICME) efforts can be utilized to support component, material and process design and optimization at the earliest stages of design.

\section{Conclusions}

Extensive development and application of computational modeling methods have been applied to the processing and microstructure evolution of Alloy 718. Phenomenological and mechanistic models have been developed and applied to full-scale components. The results of many of these modeling efforts show good to excellent agreement with laboratory or full-scale material demonstrations.

Less work has been conducted in the area of mechanical property modeling, which is a major requirement for future application to component design activities. Work to link a series of modeling tools together to enable simulation of a full-scale component and microstructure through the entire manufacture sequence has been demonstrated.

There has been significant progress in the development of modeling and simulation tools for deployment into engineering activities, but further work remains to develop industry-wide standards for these engineering methods and to establish standard validation techniques to ensure accurate and reliable predictions. Methods to effectively link engineering design tools with materials and manufacturing models in an efficient and robust manner is also needed. Standard 
material property databases or methods to generate this data are needed for further industrial deployment of various modeling and simulation tools.

\section{References}

1. C. J. Kuehmann and G. B. Olson, "Computational materials design and engineering" Materials Science and Technology 2009 Vol. 25 No. 4, pp. 472-478.

2. R. Reed, T. Tao, N. Warnken, "Alloys-by-Design: Application to nickel-based single crystal superalloys”, Acta Materialia, Vol. 57, Issue 19, 2009, pp. 5898-5913

3. R. Schafrik, "Innovations in Aerospace Materials and Manufacturing Process Development", TMS Annual Meeting Seattle14 February 2010

4. R. Mitchell, J. Lemsky, R. Ramanathan, H. Li, K. Perkins, L. Connor, "Process Development and Microstructure and Mechanical Property Evaluation of a Dual Microstructure Heat Treated Advanced Nickel Disc Alloy", Superalloys 2008, TMS, 2008, pp. 347-356

5. D.U. Furrer and S.L. Semiatin, editors, Fundamentals of Modeling for Metals Processing, ASM-International Metals Handbook Volume 22A, 2009

6. C.M. Sellars: in Hot Working and Forming Processes, Edited by C.M Sellars and G.J. Davies, TMS, London, 1979, pp 3-15.

7. C. Devadas, I.V. Samarasekera, and E.B. Hawbolt, "The Thermal and Metallurgical State of Strip during Hot Rolling: Part III, Microstructural Evolution," Met. Trans. A, 12A, 1991, pp 335-349.

8. G. Shen, S.L. Semiatin, and R.Shivpuri, "Modeling Microstructural Development during the Forging of Waspaloy", Met. Trans. A, 26A, 1995, pp 1795-1802.

9. N. Warnken, A. Drevermann, D. Ma, S. Fries, and I. Steinbach, "Development of a Simulation Approach to Microstructure Evolution during Solidification and Homogenisation Using the Phase Field Method" Superalloys 2008, TMS, 2008, pp. 951-962

10. M. Vijayakumar, S.N. Tewari, James E. Lee, P.A. Curreri, “A model of solidification microstructures in nickel-based superalloys: predicting primary dendrite spacing selection", Materials Science and Engineering: A, Volume 132, February 1991, pp. 195-201

11. S. Das, A. S, I. C. Howard and E. J. Palmiere, "A general method for coupling microstructural response with structural performance”, Proc. R. Soc. A 2006 462, pp. 20852096

12. H.-J. Jou, "Microstructure Modeling of 3rd Generation Disk Alloy", NASA/CR—2008215199

13. Y.H. Wen, B. Wang, J.P. Simmons and Y. Wang, "A Phase-Field Model for Heat Treatment Applications in Ni-base Alloys”, Acta Mater. 54 (2006) pp. 2087-2099. 
14. E. Nembach and G. Neite, "Precipitation Hardening of Superalloys by Ordered GammaPrime Particles", Progress in Materials Science, Vol. 29, 1985, pp. 177-319.

15. T. M. Pollock and S. Tin, Nickel-Based Superalloys for Advanced Turbine Engines: Chemistry, Microstructure and Properties, J. Propulsion Power, 2006, 22, pp. 361-374

16. D. Furrer, A. Chatterjee, G. Shen, S. L. Semiatin, J. Miller, M. Glavicic, R. Goetz, and D. Barker, "Development and Application of Microstructure and Mechanical Property Models for Titanium Alloys", Ti2007 Science and Technology, eds. M. Minomi, S. Akiyama, M. Ikeda, M. Hagiwara, and K. Maruyama, The Japan Institute of Metals, 2007, pp. 781-788.

17. S. K. Sondhi, B. F. Dyson and M McLean, "Tension-compression creep asymmetry in a turbine disc superalloy: roles of internal stress and thermal ageing”, Acta Materialia, 2004, vol. 52, no7, pp. 1761-1772

18. Manonukul, A., Dunne, F.P.E., Knowles, D., Williams, S., "Multiaxial creep and cyclic plasticity in nickel-base alloy C263”, Intl. Jnl. of Plasticity, Vol 21, 1-20, 2005, pp 1-20.

19. D. McDowell, "Simulation-based strategies for microstructure-sensitive fatigue modeling", Materials Science and Engineering: A, Volume 468-470, Issue null, 2007, pp. 4-14

20. V. Bhamidipati, R. G. Tryon, R. Holmes, "Microstructural Models to Predict Creep Fatigue Reliability", Document Number: 2007-01-1774, in Reliability and Robust Design in Automotive Engineering, SAE International, April 2007

21. D.U. Furrer and S.L. Semiatin, editors, Metals Process Simulation, ASM-International Metals Handbook Volume 22B., to be published in 2010

22. K. Kelkar, S. Patankar and A. Mitchell, "Computational Modeling of the Electroslag Remelting (ESR) Process Used for the Production of Ingots of High-Performance Alloys", Proceeding in International Symposium on Liquid metal Processing and Casting, Santa Fe, USA, pp. 137-144, 2005

23. P. K. Sung, D. R. Poirier, S. D. Felicelli, E. J. Poirier, A. Ahmed, "Simulations of Microporosity in IN718 Equiaxed Castings", J. of Crystal Growth, 226 (2001) 363-377.

24. Y. K. Ko, V. Sahai, J. T. Berry and R. A. Overfelt, "Prediction of Porosity in Cast Equiaxed Alloy 718”, Modeling of Casting, Welding and Advance Solidification Processes VII, Eds. M. Cross and J. Campbell, TMS, 1995, pp 731-738.

25. E.D. Manson-Whitton, I.C. Stone, P.S. Grant, B. Cantor, and S. Blackham, "Solid/Liquid Coarsening Behavior of Spray Formed IN718”, TMS Annual Meeting, p 415-425, 1998, Solidification, Conference: Proceedings of the 1998 TMS Annual Meeting, February 15, 1998 - February 19, 1998 Sponsor: TMS

26. J. Mia, P.S. Grant, U. Fritsching, O. Belkessam, I. Garmendia, A. Landaberea, "Multiphysics modelling of the spray forming process", Materials Science and Engineering A 477 (2008) 2-8 
27. Andrew J Pinkerton, Richard Moat, Kamran Shah, Lin Li, Michael Preuss, Philip J Withers, "A verified model of laser direct metal deposition using an analytical enthalpy balance method." Conference Proceedings, 26th International Congress on Applications of Lasers and Electro-optics (ICALEO). 2007

28. R. Srinivasan, V. Ramnarayan, U. Desphpande, V. Jain and I Weiss, "Computer Simulation of the Forging of Fine Grain IN-718 Alloy", Metallurgical and Materials Transactions A, Volume 24, Number 9, September, 1993, pp. 2061-2069

29. Yu, Zhong-Qi; Ma, Qiu; Lin, Zhong-Qin, "Simulation and analysis of microstructure evolution of IN718 in rotary forgings by FEM" Journal of Shanghai Jiaotong University (Science), v 13 E, n 6, p 721-726, December 2008

30. Ma, Qiu, Lin, Zhong-Qin, Yu, Zhong-Qi, "Prediction of deformation behavior and microstructure evolution in heavy forging by FEM", International Journal of Advanced Manufacturing Technology, v 40, n 3-4, p 253-260, January 2009

31. D. Liu, Y.H Yang, J. Geng, and J.L Luo, "Constitutive Relationships of IN718 for Thermoviscoplastic and Microstructure Evolution Coupled Analysis", Acta. Metall. Sin., Vol. 20, No. 5, pp373-379, Oct. 2007

32. J.M. Zhang, Z.Y. Gao, J.Y. Zhuang, Z.Y. Zhong, "Modeling of grain size in superalloy IN718 during hot deformation", Journal of Materials Processing Technology, v 88, n 1, p 244-250, April 15, 1999

33. J.P. Feng, Z.J. Luo, "Method for the optimal control of forging process variables using the finite element method and control theory", Journal of Materials Processing Technology, vol. 108, no. 1, p 40-44, December 1, 2000

34. V. K. Jain and R. L. Goetz, "Determination of Contact Heat Transfer Coefficient for Forging of High Temperature Materials", Journal of Materials Shaping Technology, Volume 8, Number 3, March, 1990, pp. 1-6

35. G. Shen, D. Kahlke, R. Denkenberger, and D. Furrer, "Advances in the State-of-the-Art of Hammer Forged Alloy 718 Aerospace Components", Superalloys 718, 625, 706 and Various Derivatives, ed. E.A. Loria, TMS, 2001, 237-247.

36. V. Balassubramanian, Y.Li, T. Stotler, J.Crompton, N. Katsube, W.O. Soboyejo, "Numerical Simulation of Inertia Welding of Inconel 718", ASME Pressure Vessels Piping Div. PVP, ASME, Fairfield NJ (USA), 1997, vol. 369, pp. 289-295

37. R.P. Guest, S.Tin, “The Dynamic and Metadynamic Recrystallization of IN718”, Superalloys 718, 625, 706 and Derivatives, 2005, ed. E.A. Loria, TMS., pp. 373-383

38. J.P. Thomas, in Fundamentals of Modeling for Metals Processing, ASM-International Metals Handbook Volume 22A, editors D.U. Furrer and S.L. Semiatin, 2009, pp. 566-582 
39. Y-S Naa, J-Ta Yeoma, N-K Park, Jai-Young Lee, "Simulation of microstructures for Alloy 718 blade forging using 3D FEM simulator" Journal of Materials Processing Technology 141 (2003) 337-342

40. X. Zhao, R. P. Guest, S. Tin, D. Cole, J. W. Brooks and M. Peers, "Modelling hot deformation of Inconel 718 using state variables", Materials Science and Technology November 2004 Vol. 20, pp. 1414-1420.

41. C. Sommitsch, D. Huber, F. Ingelman-Sundberg, Stefan, Mitsche, Martin Stockinger, and Bruno Buchmayr, "Recrysallization and Grain Growth in the Nickel-Based Superalloy Allvac 718Plus”, Int. J. Mat. Res., 100 (2009) 8, pp. 1088-1098.

42. R. P. Guest and S. Tin, "Modelling Microstructural Transformations of Nickel Base Superalloy in 718 During Hot Deformation", Superalloys 718, 625, 706 and Derivatives 2005, Eds. E. A. Loria, TMS, 2005, pp. 385-397.

43. X. Zhao, R. P. Guest, S. Tin, D. Cole, J. W. Brooks and M. Peers, "Modelling hot deformation of Inconel 718 using state variables", Materials Science and Technology November 2004 Vol. 20, pp 1414-1420.

44. J.-P. Thomas, E. Bauchet, C. Dumont, and F. Montheillet, EBSD Investigation and Modeling of the Microstructural Evolution of Superalloy 718 during Hot Deformation, Superalloys 2004, Edited by K.A. Green, T.M. Pollock, H. Harada, T.E. Howson, R.C. Reed, J.J. Schirra, and S, Walston, TMS (The Minerals, Metals \& Materials Society), 2004 pp. 959960

45. Z.J. Luo, Q. Yang, D. Liu, “A novel method for predicting the grain size of superalloy forgings based on the fuzzy method and the FEM", J. of Mat. Proc. Tech., 99 (2000), pp 246-249.

46. S.C. Medeiros, Y.V.R.K. Prasad, W.G. Frazier, R. Srinivasan, "Microstructural modeling of metadynamic recrystallization in hot working of IN 718 superalloy", Materials Science and Engineering A293 (2000) 198-207

47. K. Wu, F. Zhang, S. Chen, W. Cao and Y. A. Chang, "A Modeling Tool for the Precipitation Simulations of Superalloys during Heat Treatments", Superalloys 2008, eds., R.C. Reed, K. A. Green, P. Caron, T. P. Gabb, M. G. Fahrmann, E. S. Huron, S. A. Woodard, TMS, 2008, pp 933-939.

48. D. Dye, K.T. Conlon, and R.C. Reed, "Characterization and Modeling of Quenching-Induced Residual Stresses in the Nickel-Based Superalloy IN718”, Met. Trans. A, Vol. 35A, June 2004, pp 1703-1713.

49. M.A. Rist, S. Tin, B.A. Roder, J.A. James, and M.R. Daymond, "Residual Stresses in a Quenched Superalloy Turbine Disc: Measurements and Modeling", Met. Trans. A, Vol. 37A, February 2006, pp 459-467 
50. H. Andersson, C. Persson, T. Hansson, S. Melin and N. Jarvstrat, "Constitutive dependence in finite-element modelling of crack closure during fatigue", Fatigue Fract Engng Mater Struct. 27, 2004, 75-87

51. R. A. Claudio, C. M. Branco, E. C. Gomes, J. Byrne, G. F. Harrison, and M. R. Winstone, "Fatigue Life Prediction and Failure Analysis of a gas turbine disc using the finite element method", Fatigue Fract Engng Mater Struct, 27, 2004, 849-860

52. M. Rauch and E. Roos, "Life assessment of multiaxially cyclic loaded turbine components", Fatigue Fract Engng Mater Struct, 31, 2008, 441-451

53. F.P.E. Dunne, A.J. Wilkinson, R. Allen, "Experimental and computational studies of low cycle fatigue crack nucleation in a polycrystal", International Journal of Plasticity, Volume 23, Issue 2, Pages 273-295

54. M. Shenoy, J. Zhang and D.L. McDowell, "Estimating fatigue sensitivity to polycrystalline Ni-base superalloy, microstructures using a computational approach”, Fatigue Fract Engng Mater Struct, 30, 889-904

55. S. Tin, P.D. Lee, A. Kermanpur, M. Rist, and M. McLean, Met. and Mat. Trans. A Vol. 36A, September 2005, pp. 2493-2504

\section{Appendix 1. Nomenclature for Equations}

$\mathrm{d}=$ grain size

$\mathrm{d}_{0}=$ initial grain size

$\sigma=$ flow stress

$\mathrm{R}=$ gas constant

$\mathrm{Q}=$ activation energy

$\mathrm{T}=$ temperature

$\varepsilon=$ strain

$\mathrm{Z}=$ Zener-Holoman parameter

$\mathrm{X}_{\mathrm{mdyn}}=$ fraction metadynamic recrystallization

$\mathrm{d}_{\mathrm{mdyn}}=$ size of metadynamic recrystallized grains

$\mathrm{X}_{\mathrm{dyn}}=$ fraction dynamic recrystallization

$\mathrm{d}_{\mathrm{dyn}}=$ size of dynamic recrystallized grains 